\title{
A mathematical model for facility location in banking industry
}

\author{
Amir Ehsani, Abolfazl Danaei* and Mohammad Hemmati
}

Department of Industrial Management, Semnan branch, Islamic Azad university, Semnan, Iran

\begin{tabular}{l}
\hline C H R O N I C L E \\
\hline Article history: \\
Received March 202014 \\
Accepted 28 July 2014 \\
Available online \\
August 8 2014 \\
\hline Keywords: \\
Facility location \\
ATM \\
Banking industry
\end{tabular}
A B S T R A C T

\begin{abstract}
This paper presents an empirical investigation to determine the efficient locations of bank branch as well as automated banking machine. The study develops a mathematical model to minimize the cost of facility establishment subject to some constraints, which are associated with the population, accessibility of facilities, etc. All input parameters are considered in terms of triangular fuzzy numbers and using some methods, they numbers are converted into crisp values. The method has been applied for four cities in province of Seman, Iran and using WinQSB, the efficient locations of the facilities for a private bank named Samen have been determined.
\end{abstract}

\section{Introduction}

During the past few years, there has been growing interest in private banking development in Iran. Most banks try to find appropriate places for lower expenses to generate more revenue (Craig, 1984; Al-Hanbali, 2003). There are literally many studies associated with facility locations of banks. Aldajani and Alfares (2009) considered the problem of determining the optimum number and locations of banking automatic teller machines (ATMs). The objective of the survey was to minimize the total number of ATMs to cover all customer demands within a given geographical area. Almossawi (2001) concentrated on determining the bank selection criteria in Bahrain. The survey examination depended on 30 selection factors extracted from relevant literature, personal experience and interviews with some bank officials and college students. They reported that the chief factors determining college students' bank selection could include bank's reputation, availability of parking space near the bank, friendliness of bank personnel, and availability and location of automated teller machines (ATM). Kaynak and Harcar (2005) showed the application of geodemographic segmentation to the service industry by applying commercial banking as a case example. They reported that there were substantial differences between customers of local and national US banks in their evaluation of the relative importance of bank service charges and overall confidence in the bank. Miliotis et al. (2002) showed how demand-covering models could be combined with geographical *Corresponding author. Tel: +989121316312

E-mail addresses: danaei11@yahoo.com (A. Danaei) 
information systems (GIS) to detect the optimal location of bank branches, taking into account the different factors that characterize local conditions within the demand area.

\section{The proposed study}

The proposed model of this paper plans to locate the places of banks and ATM in 58 different locations. Let $P$ be the population of the province and $P_{r}$ be the population of each alternative location, respectively. In addition, let $m_{j}$ be the defuzzify coefficient associated with population of each alternative. Therefore, for each alternative we define a utility parameter $a_{j}$ as follows,

$a_{j}^{1}=\frac{m_{j} P_{r}}{\sum_{j=1}^{n} m_{j} \sum_{j=1}^{s} P_{r}} \forall j=1, \cdots, n ; r=1, \cdots, s$

Let $x_{j}$ be a binary variable, which is one when a facility is located in place $j$ and zero, otherwise. Let $c_{j}$ and $d_{j}$ be the cost of each square meter of land dedicated to place $j$ and the distance of facility from the center of service, respectively.

\subsection{The objective functions}

There are two objective functions associated with the proposed study, one associated with the place a branch of bank is located as follows,

$\min z_{1}=\sum_{j=1}^{n} c_{j} x_{j}$.

In addition, the study minimizes the cost of allocating ATM to a particular place as follows,

$\min z_{2}=\sum_{j=1}^{n} d_{j} x_{j}$,

where $d_{j}$ is the distance from each service facility.

\subsection{Constraints}

The first constraint is associated with the portion of covering set of population as follows,

$\sum_{j=1}^{n}-\ln \left(-\ln \left(1-a_{j}^{1}\right)\right) x_{j} \geq-\ln (1-\alpha)$

where $\alpha$ is the level of uncertainty. Next constraint considers the level of wealth distribution.

$\sum_{j=1}^{n}-\ln \left(-\ln \left(1-a_{j}^{2}\right)\right) x_{j} \geq-\ln (1-\alpha)$,

where $a_{j}^{2}$ is associated with wealth distribution and is defined as follows,

$a_{j}^{2}=\frac{r_{j} F_{r}}{\sum_{j=1}^{n} r_{j} \sum_{j=1}^{s} F_{j}} \forall j=1, \cdots, n ; r=1, \cdots, s$

where $r_{j}$ and $F_{j}$ are defuzzify ratio of wealth and availability of money in each location, respectively. Depending on the position of each alternative, we have

$\sum_{j=1}^{n}\left(-\ln \left(a_{j}^{i}\right)\right) x_{j} \geq-\ln (1-\alpha)$

where

$a_{j}^{i}=L+\Delta \times \frac{(m-L)(\Delta+u-m)^{2}(R-\lambda)+(u-L)^{2}(\Delta+m-\lambda)^{2}}{(\Delta+m-\lambda)(\Delta+u-m)^{2}(R-\lambda)+(u-L)(\Delta+u-m)}$, 
where $\tilde{a}_{j}^{i}$ is a triangular fuzzy number defined as $\tilde{a}_{j}^{i}=\left(\lambda_{j}, m_{j}, u_{j}\right), L=\min \left(\lambda_{j}\right), R=\max \left(u_{j}\right)$ and $\Delta=R-L$,(Zadeh, 1965; Opricovic \& Tzeng, 2003). We consider some constraint similar to what we have in Eq. (7) for infrastructure with $a_{j}^{i}=\frac{I_{j}}{\sum_{j=1}^{n} I_{j}} \forall i, j$. Finally, we consider similar constraints as we introduced in Eq. (7) and Eq. (8) for the level of easy access to facilities.

\section{The results}

The proposed model of this paper, which was formulated as a mixed integer nonlinear optimization has been coded in WinQSB software package. In our survey, there were 4 cities located in province of Semnan, Iran. In addition, we have detected 58 alternative locations for facility establishment. Fig. 1 demonstrates the position of each bank and ATM facilities located for each city.

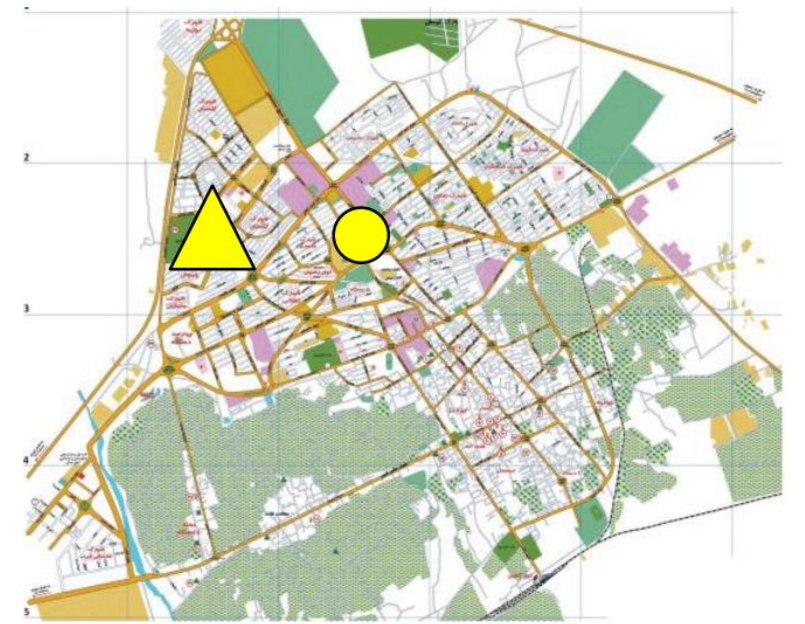

Semnan

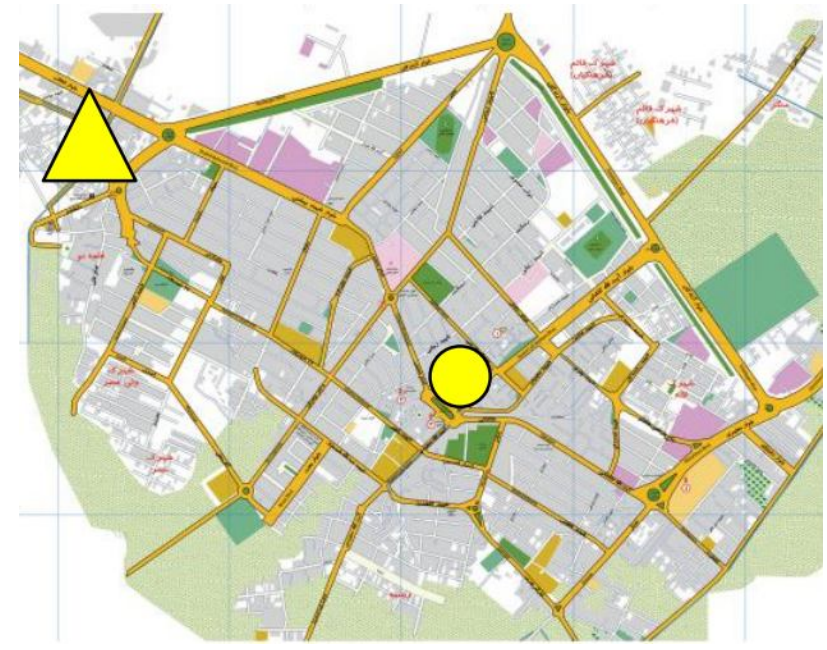

Garmsar

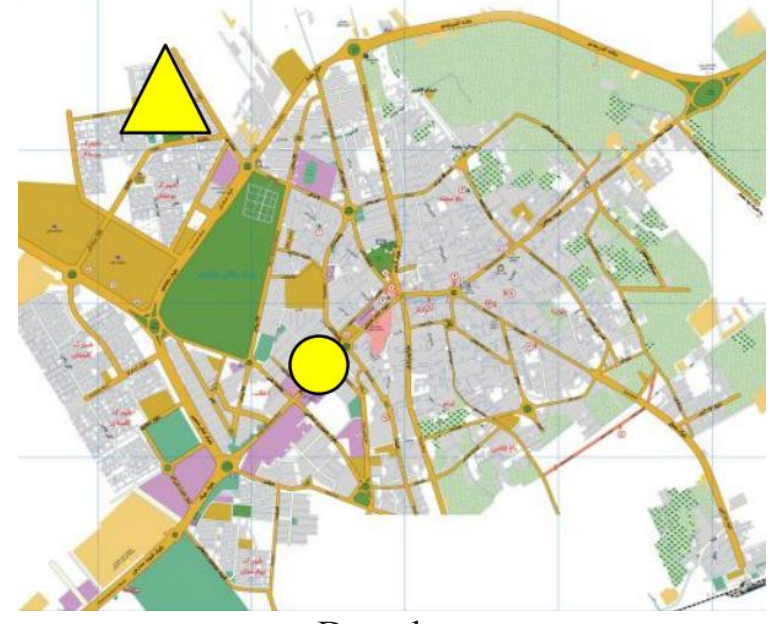

Damghan

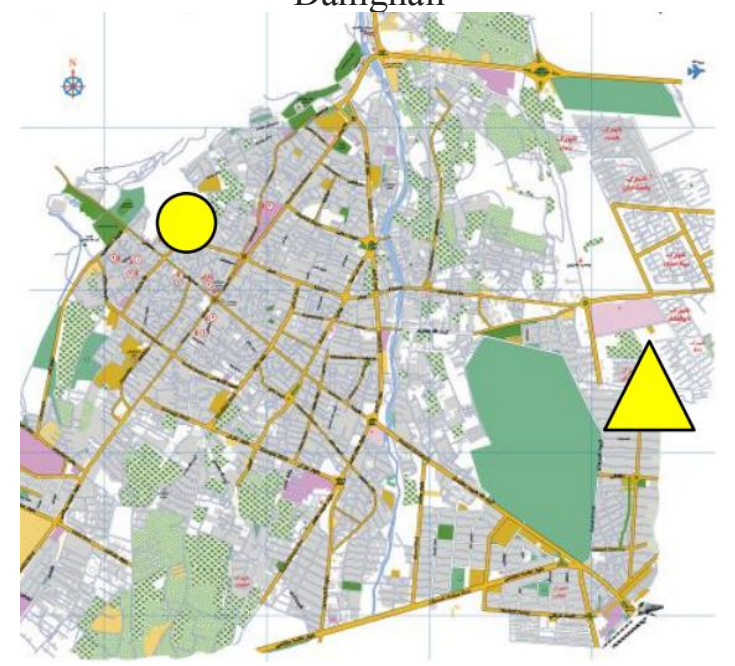

Shahrood

Fig. 2. The results of facility location

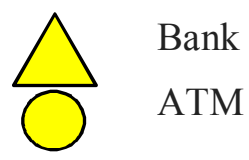




\section{Conclusion}

During the past few years, there has been growing trends on banking industry in Iran due to massive deregulation, which has facilitated the emerge of private banks. In this paper, we have presented a mathematical model to determine the optimal locations of bank branch and ATM in four cities in province of Semnan, Iran. The proposed study has implemented fuzzy logic to handle any uncertainty associated with input parameters. The preliminary results indicate that the proposed study has capable of locating new alternatives, effectively.

\section{Acknowledgement}

The authors would like to thank the anonymous referees for constructive comments on earlier version of this paper.

\section{References}

Aldajani, M. A., \& Alfares, H. K. (2009). Location of banking automatic teller machines based on convolution. Computers \& Industrial Engineering, 57(4), 1194-1201.

Al-Hanbali, N. (2003, September). Building a Geospatial database and GIS data-Model integration for Banking: ATM site location. In Commission IV Joint Workshop: Data Integration and Digital Mapping Challenges in Geospatial Analysis, Integration and Visulization II, Stuttgart, Germany, September8-9.

Almossawi, M. (2001). Bank selection criteria employed by college students in Bahrain: an empirical analysis. International Journal of Bank Marketing, 19(3), 115-125.

Craig, C. S., Ghosh, A., \& McLafferty, S. (1984). Models of the retail location process-A Review. Journal of Retailing, 60(1), 5-36.

Kaynak, E., \& Harcar, T. D. (2005). American consumers' attitudes towards commercial banks: A comparison of local and national bank customers by use of geodemographic segmentation. International Journal of Bank Marketing,23(1), 73-89.

Miliotis, P., Dimopoulou, M., \& Giannikos, I. (2002). A hierarchical location model for locating bank branches in a competitive environment. International Transactions in Operational Research, 9(5), 549-565.

Opricovic, S., \& Tzeng, G. H. (2003). Defuzzification within a multicriteria decision model. International Journal of Uncertainty, Fuzziness and Knowledge-Based Systems, 11(05), 635-652.

Zadeh, L. A. (1965). Fuzzy sets. Information and Control, 8(3), 338-353. 